\title{
INEFICACIA DE LA CLÁUSULA "DEVUELTA SIN GASTOS" O "SIN OBLIGACIÓN DE PROTESTO" EN LETRAS DE CAMBIO "A LA VISTA" O "A UN PLAZO DESDE LA VISTA" Y EN PAGARÉS "A LA VISTA"
}

\begin{abstract}
Alberto Viada Lozano ${ }^{2}$
SUMARIO: Introducción. Protesto por falta de aceptación. Protesto por falta de fecha de aceptación. Protesto por falta de pago. Cláusula "devuelta sin gastos" o "sin obligación de protesto". Ineficacia respecto de los protestos "por falta de aceptación" y "por falta de fecha de aceptación". Ineficacia de la cláusula respecto de los protestos "por falta de pago" en los documentos "pagaderos a la vista". Conclusiones.
\end{abstract}

\section{INTRODUCCIÓN}

Es un concepto comunmente aceptado que los protestos son instrumentos públicos o auténticos, otorgados con las solemnidades legales y autorizados por los competentes funcionarios.

No nos referimos en este trabajo a los protestos de cheques, cuya única causal, "falta de pago", y sus solemnidades están establecidas en el artículo 33 del Decreto con Fuerza de Ley 707 de 1982, porque respecto de los cheques no cabe la cláusula "devuelta sin gastos" o "sin obligación de protesto", ya que el artículo 13 de dicho cuerpo legal, luego de establecer las menciones que debe contener un cheque, dispone expresamente que "cualesquiera otras circunstancias o cláusulas que se agreguen al cheque, se tendrán por no escritas".

Sin embargo, podemos afirmar que el objetivo fundamental de todo protesto, incluso el de los cheques, es dejar testimonio fehaciente de un hecho negativo que, de no existir el protesto, sería imposible o por lo menos casi imposible de probar. En efecto, tal como se establece en el artículo 33 citado y en el artículo 59 de la ley 18.092 sobre letras de cambio y pagarés, los referidos efectos de comercio pueden protestarse "por falta de aceptación, por falta de fecha de aceptación y por falta de pago". O sea, todos ellos son hechos negativos, que quedan fehacientemente establecidos mediante el protesto respectivo.

Remitiéndonos, entonces, sólo a los protestos de letras de cambio y pagarés, el artículo 60 de la ley 18.092 dispone que "los protestos deberán hacerse por

\footnotetext{
${ }^{1}$ Este trabajo de investigación se basó primordialmente en las normas de la Ley 18.092 y D.F.L. 707 de 1982 , por lo que no hay bibliografia doctrinal o jurisprudencia que consignar.

2 Abogado. Profesor de Derecho Comercial, en la Escuela de Derecho de la Universidad Católica del Norte, sede Coquimbo.
} 
notarios; pero en las comunas que no sean asiento de un notario podrán efectuarse también por el Oficial del Registro Civil del lugar del pago o del lugar donde deba prestarse la aceptación, según corresponda". Y, sólo respecto de los protestos "por falta de pago", la misma ley dispone, en su artículo 71, que, "salvo instrucciones en contrario, el banco o la sociedad financiera que tenga una letra en su poder, ya como beneficiario, ya como endosatario, hará el protesto por falta de pago de acuerdo con las normas siguientes:...", señalando a continuación todas las solemnidades legales que debe cumplir y los funcionarios que deben intervenir.

Por no ser el objetivo de esta disquisición, no se hará una relación detallada de las múltiples solemnidades legales que deben cumplir los protestos, dejando en claro, eso si, que "ningún otro documento o diligencia puede suplir la omisión del protesto", como enfáticamente lo dispone el artículo 76 de la ley 18.092.

Ahora bien, conviene establecer también las ocasiones en que la ley señala la necesidad de los protestos, precisamente para aclarar los efectos que al respecto pudiera tener la cláusula "devuelta sin gastos" o "sin obligación de protesto".

\section{PROTESTO POR FALTA DE ACEPTACIÓN}

Este protesto es privativo de las letras de cambio, puesto que los pagarés no se aceptan, sino que se suscriben.

Las letras de cambio nacen a la vida jurídica con la firma del librador o girador, quien da una orden al librado, no sujeta a condición, de pagar una cantidad determinada o determinable de dinero. Y el librado puede aceptar o no aceptar esta orden, de ahí la importancia del protesto para dejar constancia fehaciente de la eventual falta de aceptación del librado. Ello porque el artículo 10 de la ley 18.092 es perentorio al disponer que "el librador garantiza la aceptación y el pago de la letra de cambio. Puede eximirse de la responsabilidad de la aceptación, pero toda cláusula por la cual se exima o limite su responsabilidad por el pago se tendrá por no escrita". Por consiguiente, el legítimo portador de la letra de cambio que no es aceptada, de lo cual deja fehaciente constancia el protesto, no podrá cobrársela al librado, sino que deberá dirigirse en contra del librador o de los otros posibles obligados como endosantes o avalistas, puesto que el artículo 79 de la ley 18.092 es meridiano al disponer que "todos los que firman una letra de cambio, sea como libradores, aceptantes o endosantes, quedan solidariamente obligados a pagar al portador el valor de la letras, más los reajustes e intereses en su caso". Además, como "el aval es un acto escrito y firmado en la letra de cambio, en una hoja de prolongación adherida a ésta, o en un documento separado, por el cual el girador, un endosante o un tercero garantiza, en todo o en parte, el pago de ella", si no existe aceptante porque el librado no la firmó como tal, al tenedor de la misma, repito, sólo le caben acciones contra el librador y eventuales endosantes y avalistas de ellos. 
La aceptación es el acto por el cual el librado acata la orden del librador de pagar al portador el valor de la letra a su vencimiento. Es un acto escrito en la misma letra de cambio; debe dejarse constancia de ello por medio de las palabras "acepto", "aceptada" u otras equivalentes y la firma del librado. La sola firma del librado puesta en el anverso de la letra importa aceptación. El propietario o tenedor de la letra de cambio debe presentarla a la aceptación, sea por sí o por mandatario especial, aun cuando no la haya endosado a favor de éste. La mera tenencia de la letra hace presumir el mandato y confiere la facultad necesaria para presentarla a la aceptación y, en su defecto, requerir el protesto. La presentación de la letra de cambio a su aceptación debe hacerse en el domicilio o residencia del librado, a menos que se señale en el mismo documento otro lugat determinado para ello.

Si una letra de cambio se girare contra varias personas, todas ellas se considerarán librados, a menos que expresamente se hubiere designado algún orden, en cuyo caso se entenderá como librado sólo al que aparezca en primer lugar en el documento, y los demás como librados subsidiarios en el orden señalado. En todo caso, habiendo varios librados, cualquiera sea la forma en que estén designados, el que acepta se obliga al pago de la letra. El portador de este tipo de letras de cambio deberá requerir el protesto por falta de aceptación respecto de aquellos librados que no la aceptaren, y, si se ha establecido un orden, deberá presentarla a su aceptación en el orden fijado, y requerir su protesto por falta de aceptación a medida que se vayan negando, hasta que uno de ellos la acepte.

La ley 18.092, en su artículo 39, establece una norma especial sobre la oportunidad de la aceptación, que estimo conveniente transcribir: "La letra puede ser aceptada antes que el girador haya estampado su firma, o mientras el título esté incompleto -lo que ocurre normalmente en las compras con precio, o parte de él, pagadero a plazo-; también puede serlo después del protesto por falta de aceptación, o después de vencida o de haber sido protestada por falta de pago".

De todos modos, en lo relativo al contenido de la aceptación, la norma básica está establecida en el artículo 42 de la ley citada: "La aceptación debe ser pura y simple, pero el librado puede restringirla a una parte de la suma librada". En este caso, el tenedor de la letra de cambio deberá requerir el protesto por falta de aceptación del saldo.

Veamos ahora, dentro de los límites específicos de este trabajo, las normas legales especiales sobre documentos "a la vista", o "desde la vista", y su protesto por falta de aceptación:

El inciso segundo del artículo 35 de la tantas veces citada Ley 18.092, dispone: "La letra girada a un plazo desde la vista, y que no sea aceptada en el plazo de un año a partir de la fecha de giro, quedará sin valor, a menos de ser protestada oportunamente por falta de aceptación o de fecha de aceptación". Y el artículo 40 de la misma ley aclara: "Si una letra pagadera a un plazo de la vista se protesta por 
falta de aceptación y el librado posteriormente la acepta, el vencimiento de la letra se contará desde la fecha del protesto".

\section{PROTESTO POR FALTA DE FECHA DE ACEPTACIÓN}

Este protesto también es exclusivo de las letras de cambio, no de los pagarés, y sólo de algunas letras de cambio. Veamos:

El artículo 36 de la ley 18.092 dice que si la letra fuere girada a un plazo contadero desde la vista, o si ella debe ser presentada a la aceptación dentro de un plazo determinado en virtud de cláusulas especiales, el librado deberá fechar la aceptación. Esta fecha deberá ser la del día en que la aceptación fuese dada, a menos que el requirente exija que se ponga la del día de su presentación. Esto porque el artículo 41 aclara que el librado debe prestar o negar su aceptación en el día que el portador le presente la letra al efecto, salvo que aquél exija que se le haga una segunda presentación al día siguiente.

Pues bien, el inciso tercero del artículo 36 citado dispone: "A falta de fecha, el portador, para conservar sus derechos contra los endosantes y el librador, debe protestar la letra. El término para pagar la letra girada a un plazo contadero desde la vista correrá, en este caso, a partir del día del protesto".

O sea, aunque el librado acepte este tipo de letra de cambio, si no señala la fecha en que dicha aceptación se produce, no se sabe cuál sería la fecha de vencimiento de la misma, razón por la cual la ley exige que se proteste por falta de fecha de aceptación.

Concordando con todo lo expuesto respecto de los protestos por "falta de aceptación" o "por falta de fecha de aceptación", el inciso primero del artículo 50 de la misma Ley 18.092 dispone: "El término de la letra girada a cierto plazo a contar la vista, corre desde el día de su aceptación o desde su protesto por falta de aceptación o por falta de fecha de aceptación".

\section{PROTESTO POR FALTA DE PAGO}

A diferencia de los anteriores, las normas relativas a estos protestos son aplicables tanto a la letra de cambio como a los pagarés, puesto que el artículo 107 de la tantas veces citada ley 18.092 dispone: "En lo que no sean contrarias a su naturaleza y a las disposiciones del presente Título son aplicables al pagaré las normas relativas a la letra de cambio". Ya dijimos que las disposiciones sobre protestos por "falta de aceptación" y por "falta de fecha de aceptación" no eran aplicables al pagaré, porque son contrarias a su naturaleza, ya que en el pagaré no interviene ningún librado o aceptante, no hay aceptación, sino que es un título que nace completo a este respecto con la firma del suscriptor. Y la única norma especial contenida en el Título II de esta ley, "Del Pagaré", que tiene relación con los 
protestos, se refiere exclusivamente a los protestos por "falta de pago" y está contenida en los dos incisos finales del artículo 105, que dicen:

"El pagaré puede tener también vencimientos sucesivos, y en tal caso, para que el no pago de una cuota haga exigible el monto total insoluto, es necesario que así se exprese en el documento".

"Si nada se expresare al respecto, cada cuota morosa será protestada separadamente".

El protesto por falta de pago, como ya vimos, además de efectuarlos los notarios o los oficiales del Registro Civil del lugar del pago, cuando fuere una comuna que no sea asiento de un notario, también puede hacerlo el banco o la sociedad financiera que tenga la letra de cambio o pagaré en su poder, ya como beneficiario, ya como endosatario, salvo instrucciones en contrario, (que la práctica ha demostrado que siempre existen).

En forma similar a lo mencionado respecto de la aceptación, el portador de una letra de cambio pagadera a día fijo, a un determinado plazo contado desde la fecha, o desde la vista, o el portador de un pagaré pagadero a día fijo y determinado o a un plazo contado desde su fecha, debe presentar el respectivo documento para el pago el día de su vencimiento o al día siguiente hábil si fuere éste festivo o feriado bancario. Y si el pagaré tuviere vencimientos sucesivos, su portador deberá presentarlo para el pago en cada uno de sus vencimientos, requiriendo el protesto en cada uno de ellos si no fueren pagados, a menos de expresarse en el pagaré que el no pago de una de las cuotas haga exigible el monto total insoluto, en cuyo caso bastará sólo un protesto por la totalidad del saldo insoluto al vencimiento de la cuota impaga.

En el caso de letras de cambio o pagarés con vencimientos "a la vista", en que son pagaderos a su presentación, el portador deberá presentarlos para su pago "dentro del plazo de un año contado desde la fecha de su giro", como se desprende claramente de lo dispuesto en el artículo 49, inciso segundo del artículo $52 \mathrm{y}$ artículos 106 y 107 de la citada ley 18.092.

El inciso segundo del artículo 54 de la misma ley aclara que "el portador no puede rehusar un pago parcial. Después de vencida la letra podrá rechazarlo si fuere inferior a la mitad del valor del documento. El librado puede exigir que se haga mención de este pago en la letra y, además, que se le otorgue recibo. El portador puede protestar la letra por el saldo no pagado".

El inciso segundo del artículo 79 de la ley 18.092, luego de establecerse la obligación solidaria de todos los firmantes de una letra de cambio o pagaré de pagarlos a su vencimiento, aclara:

"Si no se realiza en tiempo y forma el protesto por falta de pago, caducarán las acciones cambiarias que el portador pueda tener en contra del librador, endosante y los avalistas de ambos. No obstante, no caducarán esas acciones en 
caso de quiebra del librado o aceptante ocurrida antes del vencimiento, o de haberse estampado en la letra la cláusula "devuelta sin gastos" o "sin protesto".

Ello nos lleva directamente al tema fundamental de este trabajo.

\section{CLÁUSULA "DEVUELTA SIN GASTOS" O "SIN OBLIGACIÓN DE PROTESTO".}

Al iniciar la exposición de esta materia no debemos olvidar que, conforme al artículo 107 de la ley 18.092, las normas de la letra de cambio rigen en todo la reglamentación del pagaré, salvo que fueren contrarias a su naturaleza o las disposiciones del Título II de la misma ley, que trata del pagaré. Por consiguiente, cada vez que se transcriba una disposición legal en que se mencione una letra de cambio, debe entenderse referida también al pagaré, salvo que sea contrario a su naturaleza, como ser las normas relativas a la aceptación o indicación de fecha de aceptación, que ya vimos que eran privativas de la letra de cambio, no aplicables al pagaré.

Pues bien, sabemos que los artículos $1^{\circ}$ y 102 de la Ley 18.092 establecen las enunciaciones que debe contener toda letra de cambio y todo pagaré, respectivamente, y que, conforme a los artículos $2^{\circ}$ y 103 , el documento en que no se cumpla con tales exigencias no valdrá como letra de cambio o como pagaré, sin perjuicio que, como lo permite el artículo 11 de la misma ley, cualquier tenedor legítimo podrá incorporarlas antes del cobro, sujetándose en todo ello a las instrucciones que haya recibido de los obligados al pago. Estas son, repito, las menciones obligatorias de toda letra de cambio o pagaré, que jamás pueden faltar para que el documento pueda tener valor jurídico como tal.

Pero el artículo 13 de la Ley 18.092 dispone que: "Además de las menciones indicadas en el artículo $1^{\circ}$, la letra de cambio puede contener:...", señalando varias cláusulas especiales y concluyendo: "...5. Otras menciones que no alteren la esencia de la letra". Entre las cláusulas o menciones específicas permitidas por este artículo está la que nos ocupa, esto es:

Además de las menciones indicadas en el artículo $1^{\circ}$ y 102 de la ley 18.092 , la letra de cambio y el pagaré pueden contener:

\section{"4.- La cláusula "devuelta sin gastos" o "sin obligación de protesto"."}

Entiendo que no puede utilizarse ninguna expresión equivalente a las establecidas en la ley, puesto que se trata de una norma de excepción que debe interpretarse y aplicarse restrictivamente. La ley no permite en este caso expresiones equivalentes, como, por ejemplo, lo hace en el artículo 18: "...si el librador ha insertado en la letra las palabras "no endosable" o una expresión equivalente..."; o en el artículo 21: "...Importa mandato para el cobro, cuando contiene la cláusula "valor en cobro", "en cobranza" u otra equivalente", o "Importa constitución en 
prenda cuando incluye la cláusula "valor en prenda", "valor en garantía" u otra equivalente"; o el artículo 33: "La aceptación debe constar en la letra misma por medio de las palabras "acepto", "aceptada" u otras equivalentes...". En cambio, reitero, la ley no contempla la posibilidad de utilizar expresiones equivalentes respecto de la cláusula "devuelta sin gastos" o "sin obligación de protesto", si bien esta última expresión puede resumirse en "sin protesto", según se desprende de la mención que de la misma hacen los artículos 74 y 79 de la misma ley.

Ahora bien, aunque la ley permite expresamente esta cláusula, no explica en qué consiste, o qué quiere decirse con ella. El artículo 74 señala: "La cláusula "devuelta sin gastos" o "sin protesto" y la que fija el plazo para presentar a la aceptación, puestas por el librador, producen efectos respecto de todos los firmantes de la letra. Estampadas por algún otro obligado, sólo producen efectos respecto de éste". Pero todavía no sabemos cuáles serían esos efectos. Para ello tendremos que recurrir al ya citado inciso segundo del artículo 79 de la ley 18.092, que dispone:

"Si no se realiza en tiempo y forma el protesto por falta de pago, caducarán las acciones cambiarias que el portador pueda tener en contra del librador, endosante y los avalistas de ambos. No obstante, no caducarán estas acciones en caso de quiebra del librado o aceptante ocurrida antes del vencimiento, o de haberse estampado en la letra la cláusula "devuelta sin gastos" o "sin protesto".

No existe ninguna otra disposición legal relativa a los efectos de la cláusula en estudio.

Por ello, podríamos concluir que el único efecto que la ley le asigna a la cláusula "devuelta sin gastos" o "sin obligación de protesto" es impedir que se produzca la caducidad de las acciones cambiarias que el portador de una letra de cambio o pagaré pueda tener en contra del librador de la letra de cambio, o de los endosantes o avalistas de ambos documentos, (salvo el o los avalistas del aceptante de la letra de cambio o del suscriptor del pagaré, porque respecto de ellos no se produciría caducidad), en el evento de que tales documentos no se hubieran protestado en tiempo y forma por "falta de pago".

Dicho de otro modo, puesto que el artículo 76 de la ley 18.092 declara enfáticamente que "ningún otro documento o diligencia puede suplir la omisión del protesto", si el aceptante de una letra de cambio o el suscriptor de un pagaré no pagare su valor a su vencimiento y no se protestare el documento "por falta de pago", o dicho protesto no se efectuare en la oportunidad establecida en la ley, o no se cumplieren todas las solemnidades legales para la validez del protesto, caducarán las acciones cambiarias que el portador pudiere tener en contra del librador de la letra de cambio, contra los endosantes de la letra de cambio o del pagaré, y contra los avalistas del librador y endosantes, a menos que el documento contenga la cláusula "devuelta sin gastos" o "sin obligación de protesto". 
Por lo mismo que éste sería el único efecto reconocido en la ley para esta cláusula, me permito sugerir que, aunque el título de crédito contenga la cláusula "devuelta sin gastos" o "sin obligación de protesto", dicha cláusula sería ineficaz ante la omisión de protestos "por falta de aceptación" o "por falta de fecha de aceptación". Es más, creo que sería absolutamente ineficaz respecto de todo protesto, incluso "por falta de pago", en las letras de cambio y pagarés con vencimiento "a la vista". Veamos:

\section{INEFICACIA RESPECTO DE LOS PROTESTOS "POR FALTA DE ACEPTACIÓN" Y "POR FALTA DE FECHA DE ACEPTACIÓN"}

El primer argumento para considerar ineficaz la cláusula "devuelta sin gastos" o "sin obligación de protesto" respecto del protesto "por falta de aceptación" o "por falta de fecha de aceptación" está en que la norma ya transcrita del inciso segundo del artículo 79 de la ley 18.092, que señala el efecto de esta cláusula, es una norma de excepción y, por ende, debe interpretarse y aplicarse restrictivamente. La norma general es la del artículo 76, según la cual "ningún otro documento o diligencia puede suplir la omisión del protesto", y, en lo que se refiere al efecto de la omisión del protesto "por falta de pago", o su ejecución inoportuna o carente de alguna solemnidad legal, lo establece el inciso segundo del artículo 79: "...caducarán las acciones cambiarias que el portador pueda tener en contra del librador, endosante y los avalistas de ambos". Y sólo respecto de este efecto, "si no se realiza en tiempo y forma el protesto por falta de pago...", la ley contempla la aplicación de la cláusula "devuelta sin gastos" o "sin protesto", estableciendo la limitadísima excepción de que, de haberse estampado esta cláusula en el documento, no caducarían las acciones cambiarias del portador en contra del librador, endosantes y avalistas de ellos.

Esto nos lleva a concluir que, si este excepcionalísimo efecto de la cláusula se refiere sólo a la omisión en tiempo y forma del protesto "por falta de pago", los demás protestos siguen la regla general de que "ningún otro documento o diligencia puede suplir la omisión del protesto", y, en consecuencia, la cláusula "devuelta sin gastos" o "sin obligación de protesto" sería ineficaz respecto de los protesto "por falta de aceptación" o "por falta de fecha de aceptación".

Otro argumento en pro de la ineficacia de la cláusula respecto de estos protestos está en sus distintas finalidades y consecuencias. Así, si bien también tiene por efecto salvaguardar las acciones cambiarias en contra del librador, endosantes y avalistas de ellos, estos protestos son indispensables para establecer la fecha del vencimiento de las letras giradas a un plazo contado desde la vista.

El artículo 50 de la ley 18.092 dispone que "el término de la letra girada a cierto plazo a contar de la vista, corre desde el día de su aceptación o desde su protesto por falta de aceptación o por falta de fecha de aceptación". Asimismo, el 
inciso tercero del artículo 36 de la misma ley ya había establecido que, "a falta de fecha, el portador, para conservar sus derechos contra los endosantes y el librador, debe protestar la letra. El término para pagar la letra girada a un plazo contadero desde la vista correrá, en este caso, a partir del día del protesto". En ninguna de estas normas legales se insinúa siquiera la posibilidad de evitar el protesto, o los efectos de su omisión en tiempo y forma, mediante la cláusula "devuelta sin gastos" o "sin obligación de protesto" ${ }^{3}$.

Por último, es de suma importancia transcribir la norma del inciso segundo del artículo 35 de la Ley 18.092, que dispone:

"La letra girada a un plazo contado desde la vista, y que no sea aceptada en el plazo de un año a partir de la fecha de giro, quedará sin valor, a menos de ser protestada oportunamente por falta de aceptación o de fecha de aceptación".

Aquí nos encontramos con que el protesto "por falta de aceptación" o "por falta de fecha de aceptación" es una solemnidad de la letra de cambio, puesto que su omisión en tiempo y forma acarrea la nulidad de la letra de cambio, "quedará sin valor". Esa omisión no afecta sólo a la determinación de la fecha de vencimiento o a la caducidad de las acciones cambiarias del portador contra el librador, endosantes y sus avalistas, sino que pierde valor también en contra del librado, o del aceptante que omitió señalar la fecha de la aceptación. Y es obvio que no cabe aplicar en este caso una cláusula de "devuelta sin gastos" o "sin obligación de protesto", porque resulta evidente que "ningún otro documento o diligencia puede suplir la omisión del protesto", obviamente efectuado en tiempo oportuno y cumpliendo con todas las solemnidades legales.

Puede llegarse a la conclusión, entonces, de que la cláusula "devuelta sin gastos" o "sin obligación de protesto" resulta ineficaz respecto de las obligaciones de protesto "por falta de aceptación" y "por falta de fecha de aceptación" de las letras de cambio.

\section{INEFICACIA DE LA CLÁUSULA RESPECTO DE LOS PROTESTOS "POR FALTA DE PAGO" EN LOS DOCUMENTO PAGADEROS "A LA VISTA".}

Tanto la letra de cambio como el pagaré pueden emitirse con diversos vencimientos, pero el primero que se establece en la reglamentación de ambos es: "A la vista", (artículo 48 para la letra de cambio y artículo 105 para el pagaré, ambos de la Ley 18.092.-). Ello significa que dichos títulos son pagaderos "a su presentación", como lo declara enfáticamente el artículo 49 de la ley citada.

El documento exclusivamente "a la vista", que no contempla en su reglamentación ningún otro tipo de vencimiento, es el cheque, a pesar que,

3 El subrayado es nuestro. 
conforme al inciso tercero del artículo 11 del Decreto con Fuerza de Ley 707 de 1982, que lo rige, "el cheque dado en pago se sujetará a las reglas generales de la letra de cambio, salvo lo dispuesto en la presente ley". Pero resulta evidente su exclusivo vencimiento "a la vista" de la propia definición que de él da el artículo 10 del citado Decreto con Fuerza de Ley: "El cheque es una orden escrita y girada contra un Banco para que éste pague, a su presentación, el todo o parte...", agregando en el inciso segundo: "El cheque es siempre pagadero a la vista. Cualquiera mención contraria se tendrá por no escrita. El cheque presentado al cobro antes del día indicado como fecha de emisión, es pagadero el día de la presentación".

Pues bien, llama la atención que, pese a su vinculación reglamentaria con la de la letra de cambio, como lo dijimos al inicio de este trabajo, el cheque, documento exclusivamente "a la vista", no contemple la posibilidad de incorporarle la cláusula "devuelta sin gastos" o "sin obligación de protesto". Es más, si la contuviere, resultaría ineficaz, textualmente: "...se tendrá por no escrita". Y como el único protesto de que puede ser objeto un cheque es "por falta de pago", ello nos lleva a considerar que también podría ser ineficaz dicha cláusula en las letras de cambio y pagarés "a la vista", en que se hubiera omitido el protesto en tiempo y forma "por falta de pago".

En todo caso, dentro de la reglamentación propia de la letra de cambio y, por ende, del pagaré, encontramos una norma que nos lleva a concluir lo que insinuamos, esto es: que la cláusula "devuelta sin gastos" o "sin obligación de protesto" resulta ineficaz en los títulos con vencimiento "a la vista", pues no permitiría subsanar la falta de protesto "por falta de pago", evitando la caducidad de las acciones cambiarias del portador en contra del librador de la letra de cambio, o de los endosantes y avalistas, en su caso, que es el único efecto que le reconoce expresamente la ley a dicha cláusula.

Dicha norma legal es el artículo 49 de la ley 18.092, que ordena:

"La letra a la vista es pagadera a su presentación, y si no fuere pagada dentro del plazo de un año contado desde la fecha de su giro quedará sin valor a menos de ser protestada oportunamente por falta de pago".

Resulta evidente, entonces, que la consecuencia en este caso de la omisión del protesto "por falta de pago", en tiempo y forma, no es la caducidad de las acciones cambiarias del portador contra el librador, endosantes y avalistas de ellos, único efecto subsanable mediante la cláusula en estudio, sino que acarrea la nulidad de la letra de cambio o pagaré. De ahí que resulta ineficaz, respecto de las letras de cambio o pagarés con vencimiento "a la vista", la cláusula "devuelta sin gastos" o "sin obligación de protesto", debiendo regir en forma absoluta la norma del artículo 76 de la ley 18.092: "Ningún otro documento o diligencia puede suplir la omisión del protesto". 


\section{CONCLUSIONES}

a) La cláusula "devuelta sin gastos" o "sin obligación de protesto" tiene la única finalidad de evitar la caducidad de las acciones cambiarias que el portador de una letra de cambio o pagaré pudiera tener en contra del librador de una letra de cambio y sus avalistas, y en contra de los endosantes de una letra de cambio o pagaré y los avalistas de ellos, si no se realiza en tiempo y forma el protesto "por falta de pago".

b) Dicha cláusula -"devuelta sin gastos" o "sin obligación de protesto"resulta ineficaz ante la omisión en tiempo y forma, de los protestos "por falta de aceptación" o "por falta de fecha de aceptación" que proceden respecto de una letra de cambio.

c) Tampoco resulta eficaz la cláusula "devuelta sin gastos" o "sin obligación de protesto" en relación a los efectos que la ley atribuye a la omisión del protesto, oportuno y con todas las solemnidades legales, "por falta de pago", respecto de las letras de cambio y pagarés con vencimiento "a la vista". 